\title{
RANCANG BANGUN QOS (QUALITY OF SERVICE) JARINGAN WIRELESS LOCAL AREA NETWORK MENGGUNAKAN METODE NDLC (NETWORK DEVELOPMENT LIFE CYCLE) DI PT TRIMITRA KOLABORASI MANDIRI (3KOM)
}

\author{
Fauyhi Eko Nugroho' ${ }^{1}$ Yeni Daniarti ${ }^{2}$ Rosidin $^{3}$ \\ 1,2,3 Program Studi Teknik Informatika, Fakultas Teknik, Universitas Muhammadiyah Tangerang \\ Jl. Perintis Kemerdekaan 1/33 Cikokol Kota Tangerang \\ Co Responden Email: fauyhi@gmail.com
}

Article history

Received Jan 26, 2021

Revised Feb 12, 2021

Accepted Feb 22, 2021

Available online Feb 27, 2021

Keywords

Bandwidth, Queue Tree, Quality of Service, QoS, Peer Connection Queue, PCQ, Mikrotik, Delay, Jitter, Throughput, Network Development Life Cylce (NDLC).

Riwayat

Diterima 25 Jan 2021

Revisi 12 Feb 2021

Disetujui 22 Feb 2021

Terbit 27 Feb 2021

Kata Kunci

Bandwidth, Queue Tree, Quality of Service, QoS, Peer Connection Queue, PCQ Mikrotik, Delay, Jitter, Throughput, Network Development Life Cylce (NDLC).

\begin{abstract}
The purpose of this research is to provide good Quality of Service for all internet users in a network by managing bandwidth with Peer Connection Queue (PCQ) method using Queue Tree. The background of this research is because there is often an uneven bandwidth sharing in every user in a network that results in one user can access the internet faster and another user accesses the internet more slowly than other users. By applying the Peer Connection Queue (PCQ) method using Queue Tree, every user who accesses the internet will get an even bandwidth allocation. Testing using Mikrotik RouterBoard with multiple computers connected via wired and some devices connected over a wireless network. The results showed that bandwidth management with PCQ method using Queue Tree gives better results than without using PCQ because by using PCQ all users who are members of one network get equal bandwidth allocation between one and the other so that users feel fair. Which means the Quality of Service provided by the network provider has been very good
\end{abstract}

\section{Abstrak}

Tujuan penelitian ini adalah untuk memberikan Quality of Service yang baik bagi seluruh pengguna internet dalam suatu jaringan dengan cara memanajemen bandwidth dengan metode Peer Connection Queue (PCQ) menggunakan Queue Tree. Latar belakang penelitian ini adalah karena sering terjadi pembagian bandwidth yang tidak merata pada setiap user dalam suatu jaringan yang mengakibatkan satu user dapat mengakses internet dengan lebih cepat dan user lain mengakses internet dengan lebih lambat dibanding user lainnya. Dengan menerapkan metode Peer Connection Queue (PCQ) menggunakan Queue Tree, maka setiap user yang mengakses internet akan mendapatkan alokasi bandwidth yang merata. Pengujian menggunakan Mikrotik RouterBoard dengan beberapa komputer yang disambungkan via wired dan beberapa perangkat yang disambungkan melalui jaringan wireless. Hasil penelitian menunjukan bahwa manajemen bandwidth dengan metode PCQ menggunakan Queue Tree memberikan hasil yang lebih baik dibandingkan tanpa menggunakan PCQ sebab dengan menggunakan PCQ semua user yang tergabung dalam satu jaringan mendapatkan alokasi bandwidth yang sama rata antara satu dan yang lain sehingga pengguna merasa adil. Yang mana artinya Quality of Service yang diberikan oleh penyedia jaringan sudah sangat baik.

\section{PENDAHULUAN}

Seiring

meningkatnya pertumbuhan jaringan internet membuat semua perusahaan atau instansi harus memiliki infrastruktur jaringan untuk mendukung fasilitas dengan koneksi internet. Selain itu, didukung oleh perkembangan mobile device yang semakin canggih, maka teknologi jaringan wireless merupakan hal yang 
sangat tepat untuk menjadi sebuah infrastruktur baru dalam sebuah perusahaan atau instansi. Kemajuan teknologi informasi harus terus dimaksimalkan kualitas serta kuantitasnya. Salah satu kemajuan teknologi informasi di bidang transmisi pada saat ini selain fiber optic salah satunya adalah wireless LAN atau disingkat dengan WLAN. WLAN adalah teknologi jaringan yang tidak menggunakan perangkat kabel fisik sebagai media pengantar data yang umumnya ditemukan di dalam sebuah jaringan komputer pada masa sekarang. Teknologi ini sendiri, sesuai namanya wireless yang berarti jaringan tanpa kabel, bekerja dengan cara memanfaatkan gelombang radio sebagai media untuk melakukan interaksi atau komunikasi dengan unit komputer lain. Pada dasarnya, penggunaan WLAN pada suatu jaringan tidak jauh berbeda dengan jaringan yang menggunakan kabel fisik sebagai media transmisinya, hanya saja untuk biaya pemasangan dan instalasinya relatif lebih terjangkau

Wireless merupakan perangkat jaringan yang fleksibel, baik dari perawatan, kerapian, maupun instalasi. Wireless merupakan sebuah teknologi jaringan yang semakin meluas dan banyak diminati oleh pengguna jaringan, seperti pada lembaga ataupun instansi dan bahkan di rumahan. Hal ini dikarenakan pada jaringan wireless tidak membutuhkan kabel untuk melakukan sebuah koneksi atau menghubungkan antar komputer, proses instalasi jaringanpun cukup mudah, dan tentusaja praktis. Pada jaringan wireless dibutuhkan perangkat-perangkat wireless untuk melakukan sebuah koneksi, sehingga komunikasi antar komputer dapat saling terhubung tanpa menggunakan kabel
Berdasarkan observasi pemantauan yang dilakukan oleh penulis, pemanfaatan jaringan wireless masih belum maksimal. Masih ada beberapa tempat yang belum mendapatkan jaringan internet. Banyaknya permintaan akan akses jaringan internet itu sendiri nantinya akan dipergunakan untuk menjadi hal yang positif dimana akses internet akan mendukung kinerja serta keseharian. Penulis pada kesempatan ini akan memanfaatkan jaringan tanpa kabel atau disebut wireless atau wireless LAN (WLAN). Dalam pemanfaatan jaringan wireless bisa digunakan sistem outdoor maupun indoor. Jika pemanfaatan konfigurasi secara indoor, maka akan membutuhkan sumber daya yang banyak sesuai dengan jumlah ruangan yang ada. Jika menggunakan konfigurasi secara outdoor, maka akan lebih efisien dan hemat dikarenakan pemanfaatan wireless secara outdoor akan menggunakan sebuah akses poin yang dipancarkan ke segala arah. Atas dasar tersebut diatas, penulis melakukan penelitian berjudul "Rancang Bangun QoS (Quality of Service) Jaringan Wireless Menggunakan Metode NDLC"

\section{METODE PENELITIAN}

Metode analisis dan perancangan menggunakan Network Development Life Cycle (NDLC) Tahapan Network Development Life Cycle (NDLC) mencakup tahapan: a) Analisis, menganalisis kebutuhan untuk melakukan penelitian, permasalahan yang ada, topologi jaringan; b) Desain, merancang jaringan dalam skala waktu tertentu; c) Simulasi prototype ,melakukan eksekusi penelitian (monitoring jaringan); d) Implementasi; dan e) Manajemen pengelolaan alokasi bandwidth jaringan yang dilakukan administrator" 


\section{HASIL DAN PEMBAHASAN}

\section{Analisis Permasalahan}

Pada tahap ini dilakukan proses identifikasi konsep sistem infrastruktur PT Trimitra kolaborasi mandiri serta mendefinisikan kebutuhan sejumlah elemen atau komponen sistem tersebut, sedemikian hingga gambaran umum kebutuhan sistem dapat diketahui.

Tahapan ini akan memaparkan sejumlah aktifitas yang dilakukkan penulis untuk memperoleh suatu konsep keluaran yang diinginkan dalam penulisan ini.

Topologi Jaringan Eksisting

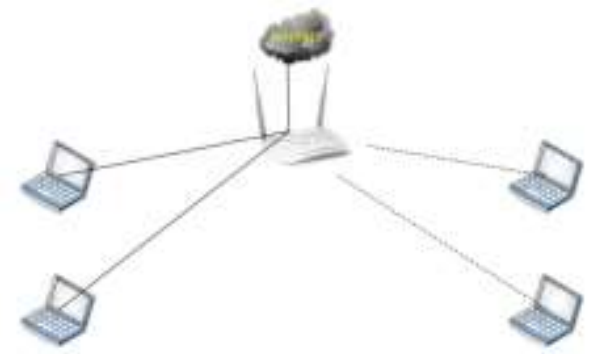

- Identifikasi

Dalam proses insfrastuktur pengembangan jaringan di PT Trimitra kolaborasi mandiri, mempunyai beberapa kondisi awal, terkait Topologi yg di terapkan dalam lingkup develop yang akan di buat, dan akan mendefinisikan awal mula dari pengembangan konsep yg akan di buat.

Dalam hal ini penulis ingin membuat suatu perbandingan yang bisa dimanfaatkkan bagi kebutuhan personal masing-masing pengguna, serta suatu pengembangan dari segi tertentu untuk menjadi salah satu solusi bagi terciptanya keamanan yang diinginkan dibandingkan standar user.

- $\quad$ Perangkat Keras

Peralatan yang digunakan dalam penelitian digolongkan menjadi dua jenis, yaitu perangkat keras (Hardware) dan perangkat lunak (Software).

\begin{tabular}{|l|l|}
\hline Perangkat & Spesifikasi \\
\hline Mikrotik RB951G-2HnD & CPU: AR9344 600MHz \\
\hline & $\begin{array}{l}\text { Main StorageNAND: } \\
\text { 64MB }\end{array}$ \\
\hline & RAM 128MB \\
\hline & RouterO5 License Level4 \\
\hline
\end{tabular}

Peralatan yang digunakan dalam penelitian digolongkan menjadi dua jenis, yaitu perangkat keras (Hardware) dan perangkat lunak (Software).

- $\quad$ Perangkat Lunak

\begin{tabular}{|l|l|}
\hline Software & Keterangan \\
\hline Windows 10 & $\begin{array}{l}\text { Sistem operasi utama PC yang } \\
\text { digunakan }\end{array}$ \\
\hline Milaotis: & RouterOS Level4 \\
\hline Winbox & Tools Remote Access \\
\hline
\end{tabular}

- Design

Perancangan ini berdasarkan tentang konsep dan gambaran yang mendeskripsikan perangkat sebenarnya dalam suatu system yang penulis gambarkan dengan topologi sebagai berikut,

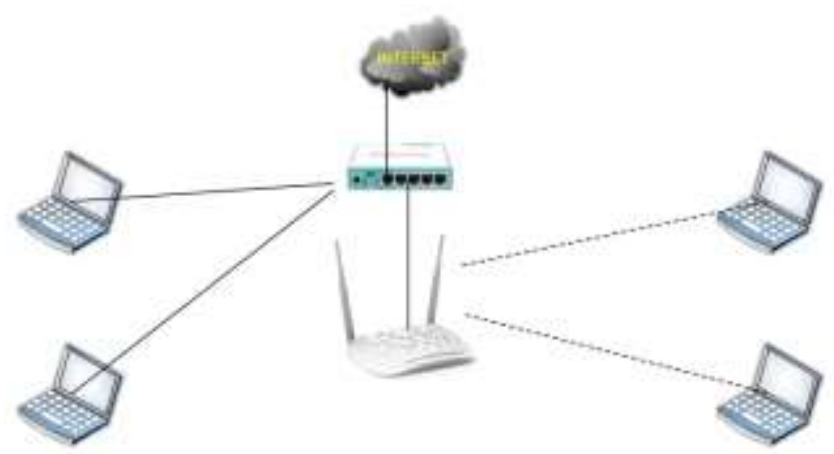

\section{- $\quad$ Prototyping}

Tahap selanjutnya adalah pembuatan prototipe sistem yang akan dibangun, sebagai simulasi dari implementasi sistem produksi, penulis membangun prototipe sistem ini pada lingkungan virtual, dengan menggunakkan mesin virtual, sebagai replikkasi dari sistem yang akan dijalankan, karena mesin virtual memungkinkan suatu program yang sudah terdedikasi pada suatu sistem, dapat berjalan pada lingkup mesin virtual tersebut.

Software mesin virtual yang digunakan adalah VMware- workstation-6.0.0-45731 yang support dengan beberapa platform Operating System (OS) yang digunakan 
dalam penelitian ini, dan berjalan dalam mesin virtual.

- Implementasi

- $\quad$ Seting Limit Alokasi Bandwidth di Jaringan Wireless

Masuk menu IP $\rightarrow$ Firewall $\rightarrow$ Tab Mangle -> tombol add. ganti Chain: Forward, Src. Address: 192.168.20.0/24, Out Interface: ether1 lalu klik OK.

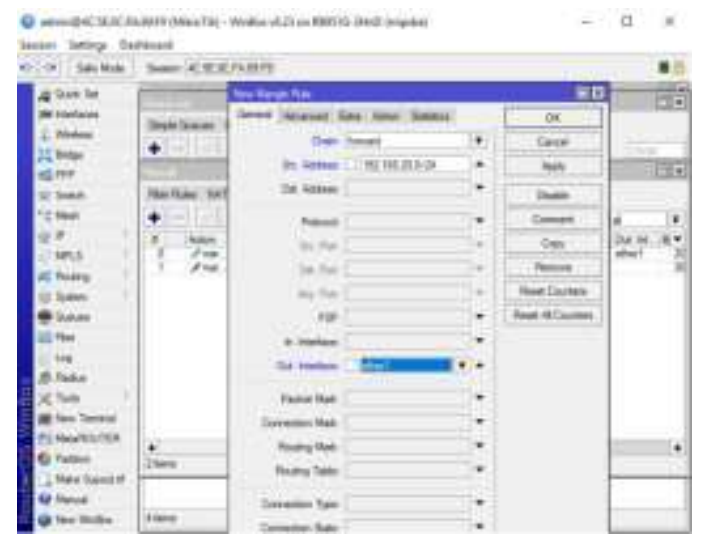

Masuk tab Action, ganti Action: mark connection, New Connection Mark: KoneksiLokalWlan lalu klik OK.

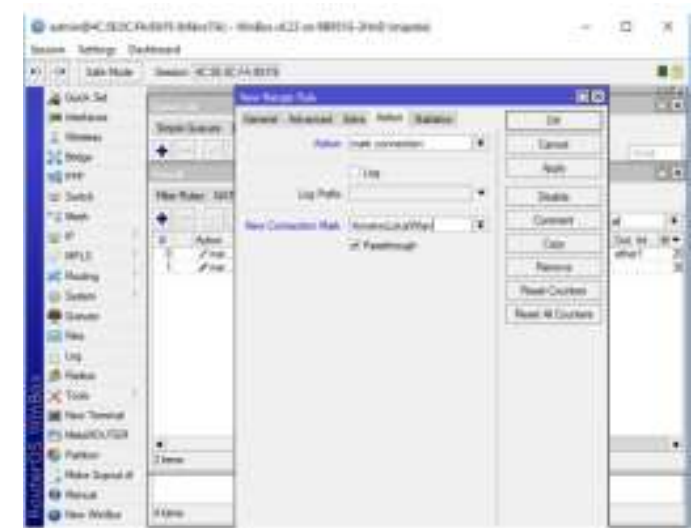

Masih di Tab Mangle, klik tombol add dan ganti Chain: forward, Connection Mark: KoneksiLokalWlan. Pilih Tab Action, ganti Action: mark packet, New Packet Mark: KoneksiLokalWlan lalu klik OK.

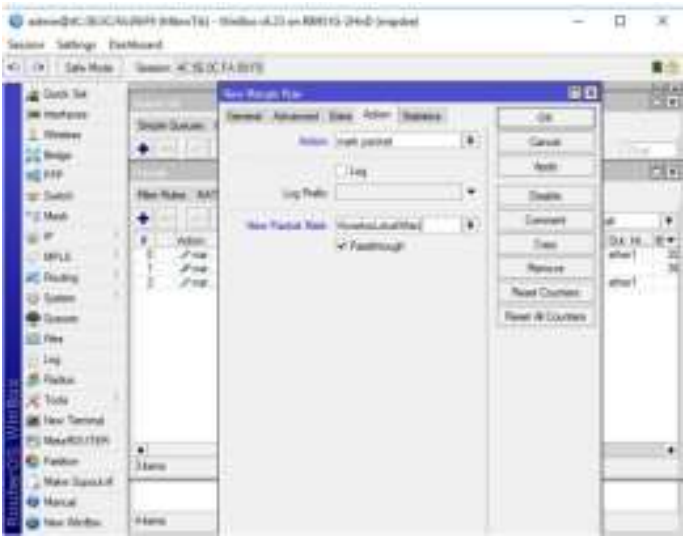

Hasilnya

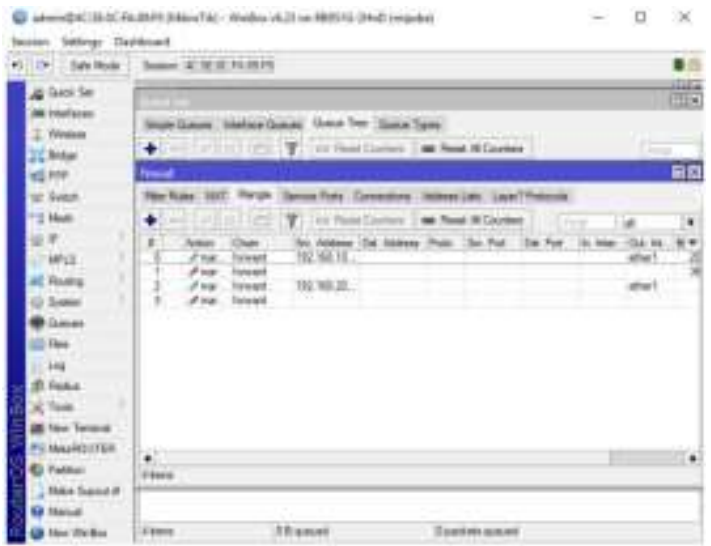

\section{- Monitoring}

Monitoring dilakukan sebagai proses pengujian yang diterapkan pada setiap fungsi di setiap komponen sistem, untuk memastikan apakah komponen sudah bekerja dengan baik dan sesuai dengan kebutuhan demi menjawab semua spesifikasi pertanyaan dan permasalahan yang dirumuskan. Pada tahap ini penulis memaparkan tentang uji coba dari aktifitas perancangan

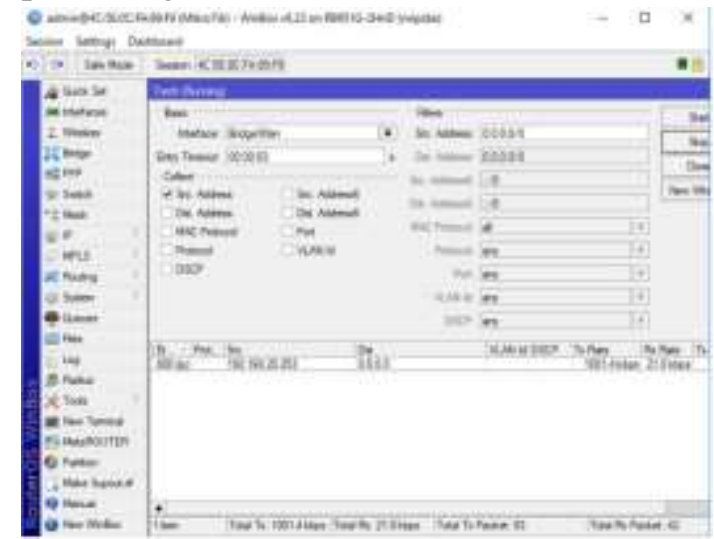


Terlihat 1 user dijaringan wireless dengan kecepatan $1 \mathrm{MB}$, Sekarang coba dengan 2 user

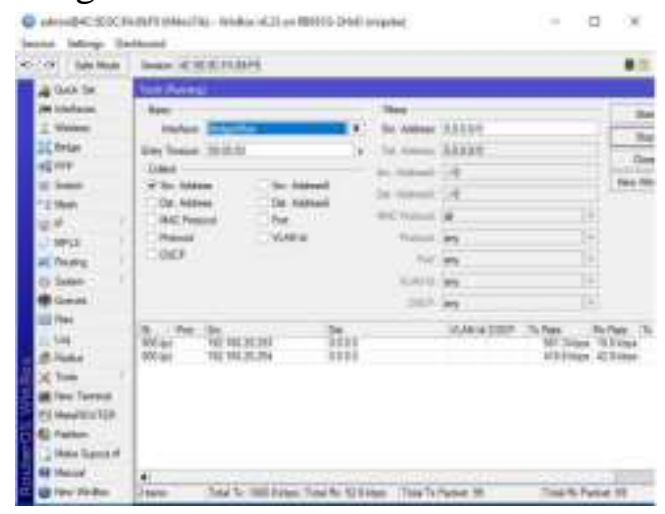

\section{- Management}

Tahap ini adalah fase akhir dari penulisan yang penulis buat, yang merupakan solusi dari hasil penelitian yang telah dipaparkan sebelumnya, yang meliputi :

Pengujian Menggunakan Wireshark Hasil capture data oleh Wireshark sebelum menggunakan Queue Tree

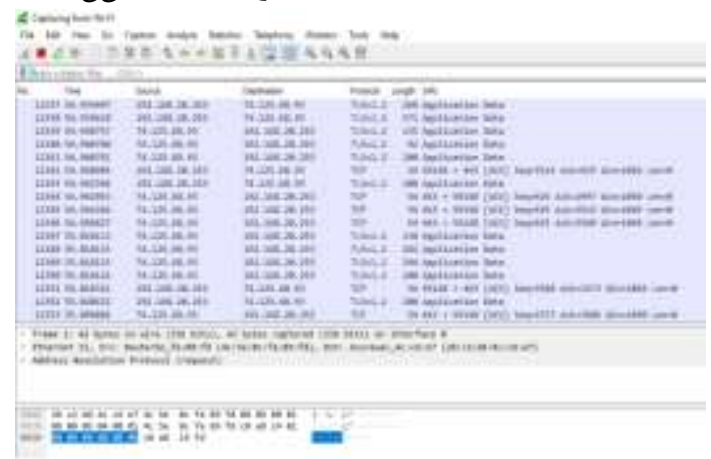

Gambar Hasil capture data menggunakan Wireshark tanpa Queue Tree dan PCQ

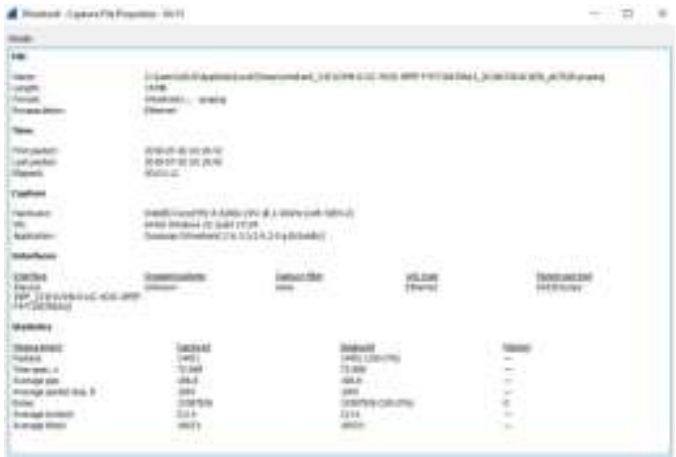

Summary pada Wireshark tanpa Queue Tree dan PCQ Hasil capture data oleh Wireshark setelah menggunakan Queue Tree

\section{KESIMPULAN}

Kesimpulan yang diperoleh setelah melakukan tahap-tahap penelitian adalah sebagai berikut:

- Queue Tree dapat membatasi bandwidth yang akan dialokasikan pada setiap jaringan.

- PCQ dapat bekerja dengan baik, setiap user bisa mendapatkan alokasi bandwidth secara merata.

\section{REFERENSI}

Pagala, Muhammad Syarif. 2017. OPTIMALISASI MANAJEMEN BANDWIDTH JARINGAN KOMPUTER MENGGUNAKAN METODE QUEUE TREE DAN PCQ (PEER CONNECTION QUEUE). Kendari : Universitas Halu Oleo.

Pratama, I Putu Agus Eka. 2015. HANDBOOK JARINGAN KOMPUTER TEORI DAN PRAKTIK BERBASISKAN OPEN SOURCE. Bandung : Informatika.

\section{Sofian, Iwan. 2017. JARINGAN KOMPUTER BERBASIS MIKROTIK. Bandung : Informatika.}

Towidjojo, Rendra. 2016. MIKROTIK KUNGFU KITAB 1. Palu: Jasakom.

Towidjojo, Rendra. 2016. MIKROTIK KUNGFU KITAB 2. Palu: Jasakom.

Towidjojo, Rendra. 2016. MIKROTIK KUNGFU KITAB 3. Palu: Jasakom. 